\title{
Genetic analysis of maternal and paternal lineages in Kabardian horses by uniparental molecular markers
}

\author{
Aliy-bek D. Khaudov ${ }^{1}$, Astemir S. Duduev ${ }^{1}$, Zaur A. Kokov ${ }^{2}$, Khazhismel K. Amshokov', \\ Mohamed Kh. Zhekamukhov ${ }^{3}$, Alexander M. Zaitsev ${ }^{4}$ and Monika Reissmann ${ }^{5, *}$ \\ ${ }^{1}$ Institute of Chemistry and Biology, Kabardino-Balkarian State University, Chernyshevskovo 173, 360004 Nalchik, \\ Russia \\ ${ }^{2}$ Institute of Physics and Mathematics, Kabardino-Balkarian State University, Chernyshevskovo 173, 360004 \\ Nalchik, Russia \\ ${ }^{3}$ Kabardino-Balkarian Research Institute of Agriculture, Kirova 224, 360004 Nalchik, Russia \\ ${ }^{4}$ All-Russian Research Institute of Horse Breeding, Ryazan region, Rybnoye district, 391105 Divovo, Russia \\ ${ }^{5}$ Abrecht Daniel Thaer-Institute for Agricultural and Horticultural Sciences, Humboldt University, Unter den \\ Linden 6, 10099 Berlin, Germany
}

\begin{abstract}
Studies of mitochondrial DNA (mtDNA) as well as the non-recombining part of the Y chromosome help to understand the origin and distribution of maternal and paternal lineages. The Kabardian horse from Northern Caucasia which is well-known for strength, stamina and endurance in distance riding has a large gap in its breeding documentation especially in the recent past. A $309 \mathrm{bp}$ fragment of the mitochondrial D-loop (156 Kabardian horses) and six mutations in Y chromosome (49 Kabardian stallions), respectively, were analyzed to get a better insight into breeding history, phylogenetic relationship to related breeds, maternal and paternal diversity and genetic structure. We found a high mitochondrial diversity represented by $64 \mathrm{D}$-loop haplotypes out of 14 haplogroups. The most frequent haplogroups were G (19.5\%), L (12.3\%), Q (11.7\%), and B (11.0\%). Although these four haplogroups are also frequently found in Asian riding horses (e.g. Buryat, Kirghiz, Mongolian, Transbaikalian, Tuvinian) the percentage of the particular haplogroups varies sometimes remarkable. In contrast, the obtained haplogroup pattern from Kabardian horse was more similar to that of breeds reared in the Middle East. No specific haplotype cluster was observed in the phylogenetic tree for Kabardian horses. On Kabardian Y chromosome, two mutations were found leading to three haplotypes with a percentage of $36.7 \%$ (haplotype HT1), 38.8\% (haplotype HT2) and 24.5\% (haplotype HT3), respectively. The high mitochondrial and also remarkable paternal diversity of the Kabardian horse is caused by its long history with a widely spread maternal origin and the introduction of Arabian as well as Thoroughbred influenced stallions for improvement. This high genetic diversity provides a good situation for the ongoing breed development and performance selection as well as avoiding inbreeding.
\end{abstract}

Keywords: Genetic diversity, Mitochondrial DNA, Phylogenetic analysis, Y chromosome.

\section{Introduction}

Molecular markers are powerful tools for detecting genetic variation and uniqueness of populations. Such knowledge helps to protect diversity, prevent inbreeding and improve the breeding process. Sequence analyses of the mitochondrial DNA (mtDNA) and the $\mathrm{Y}$ chromosome are often used for discovery of maternal and paternal lineages, for analysis of phylogenetic development and breed origin as well as for detection of population admixture (Di Lorenzo et al., 2016). The specific value of mtDNA and non-recombining $Y$ chromosomal sequences in phylogenetic investigations is caused by its clonal mode of inheritance. A study of hypervariable displacement loop (D-loop) region allows a determination of the diversity of maternal ancestry within a population and its phylogenetic relationship. Therefore, mtDNA is widely used as an instrument for uncovering the evolutional and phylogenetic history of populations like cattle (Ludwig et al., 2013), pig (Alves et al., 2003), chicken (Di Lorenzo et al., 2015) as well as horse (Forster et al., 2012; Yang et al., 2017). D-loop studies were also used for description of intrabreed and interbreed differentiation (Bowling et al., 2000; Chauhan et al., 2011). In horses, a huge amount of mitochondrial haplotypes exists and several authors developed classifications into haplogroups (Jansen et al., 2002; Cieslak et al., 2010; Achilli et al., 2012).

On other hand, mutations in the paternally transmitted portion of the $\mathrm{Y}$ chromosome can help to investigate paternal lineages. In contrast to the plenty of mutations in the mitochondrial genome and on the $\mathrm{Y}$ chromosome 
variation of pre-domestic horses (Lippold et al., 2011), no diversity was detected in the Y chromosome of domestic horses awhile (Brandariz-Fontes et al., 2013; Lindgren et al., 2004). In the last years, a few polymorphic sites were found in modern horses leading to a small number of haplotypes in contemporary domestic stallions (Ling et al., 2010; Wallner et al., 2013, 2017; Kreutzmann et al., 2014).

This study addresses the maternal and paternal genetic variation of Kabardian horses - a breed with excellent endurance for mountain rides. The Kabardian represents a relative self-contained population from Caucasus; unfortunately without clear knowledge about its origin and reliable centralized studbook registry from the end of the $1990^{\text {th }}$ years till 2007. For further breeding work, its genetic relationship to other breeds from this region as well as to breeds with good stamina performance like Arabians is of interest. Additional, the investigation of the maternal and paternal lines shall help to improve the line classification in the new studbook.

\section{Materials and Methods}

\section{Material and DNA preparation}

Blood from V. jugularis or mane hair samples were taken from 156 Kabardian horses (64 males and 92 females) kept in studs of the Kabardino-Balkarian Republic (16 studs with 24 males and 46 females), Krasnodarsky Krai (2 studs with 3 males and 14 females), Adygea (3 studs with 3 males and 9 females), Karachaevo-Cherkesskaia Republic (1 stud with 5 females) in Russia as well as in Germany (imported horses from Caucasus distributed to 9 studs with 34 males and 18 females). The horses were selected in agreement with the Kabardian horse breeding association to get a representative sample and to avoid the use of closely related horses. All paragraphs of the Federal Law on Protection of Animals against Cruel Treatment were strictly followed (Russia: No. 1571, Germany: 55.2-1-54-2532-128-2014). The genomic DNA was extracted by incubating the roots or the white cell pellets in $180 \mu \mathrm{L} \mathrm{T} 1$ buffer and $20 \mu \mathrm{L}$ proteinase $\mathrm{K}$ (Macherey-Nagel, Berlin, Germany) followed by the salting out procedure (Miller et al., 1988). Addressing the $\mathrm{Y}$ chromosome, 49 Kabardian breeding stallions from the 64 male horses used for mtDNA analysis and four stallions of the Przewalski's horse were investigated.

\section{PCR amplification and sequencing}

The amplification of the upstream D-loop region was carried out in a volume of $25 \mathrm{~mL}$ containing $50 \mathrm{ng}$ DNA, $0.2 \mu \mathrm{M}$ of each primer, $0.2 \mathrm{mM} \mathrm{dNTP}, 2.5 \mathrm{mM}$ $\mathrm{MgCl}_{2}$ and $0.5 \mathrm{U}$ GoTaqflexi polymerase (Promega, Wisconsin, USA). The procedure involved denaturation at $95^{\circ} \mathrm{C}(5 \mathrm{~min})$ followed by 35 cycles of denaturation at $94^{\circ} \mathrm{C}(30 \mathrm{~s})$, annealing at $55^{\circ} \mathrm{C}(30 \mathrm{~s})$ and elongation at $72^{\circ} \mathrm{C}(45 \mathrm{~s})$. The final elongation was carried out at $72^{\circ} \mathrm{C}$ for $5 \mathrm{~min}$. The separation of the PCR fragment from $2 \%$ agarose gel was performed with GeneJet Gel Extraction Kit (Fermentas, Thermo Fisher Scientific, Massachusetts, USA). The sequencing was carried out as Sanger reaction with BigDye Terminator v1.1 Ready Reaction Cycle Sequencing Kit in an ABI PRISM 310 Genetic Analyzer (Life technologies, Thermo Fisher Scientific, Massachusetts, USA) using manufacturer's protocol.

On Y chromosome, two polymorphic sites found on position 0147 in a prehistoric wild Siberian horse and on position 0201 in a Przewalski's horse (Lippold et al., 2011) were genotyped using pyrosequencing with $57^{\circ} \mathrm{C}$ annealing temperature in PCR reaction following manufacturer's protocol (Qiagen, Hilden, Germany). Four additional polymorphisms known from recent horses (Wallner et al., 2013) were analyzed with KBiosciences Allele Specific PCR (KASP) technology using standard procedure with $57^{\circ} \mathrm{C}$ touch down PCR (LGC Genomics, Berlin, Germany) for positions 1277 and 25345 as well as with sequencing (like described above) for positions 10594 and 11007-11315. All primer sequences are shown in Table 1.

\section{Phylogenetic analysis}

All sequences were prepared with SnapGene Viewer 2.5.0/2.6.0. The phylogenetic tree was built within MEGA 7.0.18 (Kumar et al., 2016) using a 309 bp fragment (position 15469-15777 after NC001640 from GenBank). For evaluation of haplogroup distribution and frequency in the Kabardian horse, D-loop sequences from 71 Mongolian, 22 Buryat, 24 Transbaikalian, 25 Tuvinian (GenBank JQ936335JQ936476) and 9 Kirghiz horses (own material) were used as possible closely related breeds from North Asia. For correct classification into haplogroups, 40 sequences selected for mutations in the investigated Dloop region out of 83 (GenBank JN398377-JN398457, EF597513, EF597514) were used and all haplogroups were named or renamed after Achilli et al. (2012). DnaSP software Version 6.10.03 (Rozas et al., 2017) was used for haplotype diversity estimation.

\section{Results and Discussion}

In this study, 64 different haplotypes were discovered in 156 Kabardian horses (Table 2). The Asian breeds used for comparison show also a huge number of haplotypes but with regard to the haplogroups, Kabardian horses present the highest diversity. The ratio between number of horses and number of haplotypes illustrates that on average only one to two horses within a breed share the same haplotype and underlines the high variation. With a frequency over $10 \%$, the most haplotypes of Kabardian horses are found in the haplogroups $\mathrm{G}, \mathrm{L}, \mathrm{Q}$, and $\mathrm{B}$ while Kabardian haplotypes clustered rarely in haplogroups $\mathrm{N}$ and R. No Kabardian haplotype is found in the haplogroups F, H and $\mathrm{K}$, respectively (Table 3 ). 
Table 1. Primer sequences for polymorphism detection in D-loop region and on Y chromosome.

\begin{tabular}{|c|c|c|c|}
\hline Primer name & Nucleotide sequence $5^{\prime}-3^{\prime}$ & Method & Length \\
\hline H-mtDNA F ${ }^{1)}$ & AGC TCC ACC ATC AAC ACC CAA A & Sequencing & $690 \mathrm{bp}$ \\
\hline H-mtDNA R ${ }^{1)}$ & CCA TGG ACT GAA TAA CAC CTT ATG GTT G & & \\
\hline H-Y0147 F & Biotin-ATG TCA GGA TGC CAA CTG GTC & Pyroseq & $74 \mathrm{bp}$ \\
\hline H-Y0147 R & GTG CCC ACA AGA CAA TGT C & & \\
\hline H-Y0147 S & CCA CTA GGG CCC TGT TTC & & \\
\hline H-Y0201 F & Biotin-AGT GGC CCC CTG AAG ACA TT & Pyroseq & $76 \mathrm{bp}$ \\
\hline H-Y0201 R & CGA CCG GAA AAG GGA CAG TG & & \\
\hline H-Y0201 S & GGC CAG AGC CAC TAC T & & \\
\hline H-Y1277 A1 & TTC TAA ACA GTA ATC TCA AAC TGT GAT & KASP & $57 \mathrm{bp}$ \\
\hline H-Y1277 A2 & СTT TCT AAA CAG TAA TCT CAA ACT GTG AA & & \\
\hline H-Y1277 C & GGC TTC CAT GAA TGA CTC TCG AGT T & & \\
\hline H-Y25345 A1 & AAG TTT TAC GAA AGA CAT AAA CTA CGT TAA AT & KASP & $62 \mathrm{bp}$ \\
\hline H-Y25345 A2 & GTT TTA CGA AAG ACA TAA ACT ACG TTA AAC & & \\
\hline H-Y25345 C & GAG GAT AGA TGG GGA AAA GGT TGA AAA TA & & \\
\hline H-Y10594 F') & CCC TCT GCT GAG CAT CTA GG & Sequencing & $297 \mathrm{bp}$ \\
\hline H-Y10594 R 2) & TTG GAT GAA AGG GAC AGT GA & & \\
\hline H-Y11007 F²) & CCA ACA CAC GTC AAC AGC TC & Sequencing & $444 \mathrm{bp}$ \\
\hline H-Y11007 R ${ }^{2)}$ & GGC TTA GGC CAC TGA TGG TA & & \\
\hline
\end{tabular}

Table 2. Number of horses, haplotypes and haplogroups in different breeds, haplotype diversity as well as the ratio between the number of genotyped horses and number of haplotypes.

\begin{tabular}{lccccc}
\hline \multicolumn{1}{c}{ Breed } & $\begin{array}{c}\text { Number of } \\
\text { horses (n) }\end{array}$ & $\begin{array}{c}\text { Number of } \\
\text { haplotypes (HT) }\end{array}$ & $\begin{array}{c}\text { Number of } \\
\text { haplogroups (HG) }\end{array}$ & $\begin{array}{c}\text { Haplotype diversity } \\
(\text { Hd } \pm \text { SD) }\end{array}$ & $\begin{array}{c}\text { Ratio between horses } \\
\text { and haplotypes }\end{array}$ \\
\hline Kabardian & 156 & 64 & 14 & $0.980 \pm 0.003$ & 2.4 \\
Buryat & 22 & 20 & 10 & $0.987 \pm 0.020$ & 1.1 \\
Kirghiz & 9 & 9 & 7 & $1.000 \pm 0.052$ & 1.0 \\
Mongolian & 71 & 50 & 12 & $0.987 \pm 0.005$ & 1.4 \\
Transbaikalian & 24 & 13 & 10 & $0.909 \pm 0.039$ & 1.8 \\
Tuvinian & 25 & 22 & & $0.993 \pm 0.014$ & 1.1 \\
\hline
\end{tabular}

Table 3. Haplogroup percentage (in \%) of six analyzed breeds (haplogroups $\mathrm{O}$ and $\mathrm{P}$ were not subdivided, 12 horses don't share a haplogroup, classification after Achilli et al. (2012).

\begin{tabular}{cccccccc}
\hline \multirow{2}{*}{ Haplogroup } & Kabardian & All Asian & Buryat & Kirghiz & Mongolian & Transbaikalian & Tuvinian \\
\cline { 2 - 7 } & $(\mathrm{n}=154)$ & $(\mathrm{n}=141)$ & $(\mathrm{n}=21)$ & $(\mathrm{n}=9)$ & $(\mathrm{n}=64)$ & $(\mathrm{n}=24)$ & $(\mathrm{n}=23)$ \\
\hline $\mathrm{A}$ & 6.5 & 4.9 & 0.0 & 0.0 & 6.2 & 12.5 & 0.0 \\
$\mathrm{~B}$ & 11.0 & 14.2 & 23.8 & 11.2 & 11.0 & 8.3 & 21.8 \\
$\mathrm{C}$ & 5.2 & 4.3 & 0.0 & 0.0 & 6.2 & 4.2 & 4.3 \\
$\mathrm{D}$ & 2.6 & 4.3 & 4.8 & 0.0 & 3.1 & 8.3 & 4.3 \\
$\mathrm{E}$ & 6.5 & 5.7 & 4.8 & 11.1 & 6.2 & 0.0 & 8.7 \\
$\mathrm{~F}$ & 0.0 & 0.0 & 0.0 & 0.0 & 0.0 & 0.0 & 0.0 \\
$\mathrm{G}$ & 19.5 & 11.3 & 4.8 & 11.1 & 3.1 & 45.9 & 4.3 \\
$\mathrm{H}$ & 0.0 & 2.8 & 0.0 & 0.0 & 1.6 & 0.0 & 13.1 \\
$\mathrm{I}$ & 7.2 & 2.8 & 19.0 & 0.0 & 0.0 & 0.0 & 0.0 \\
$\mathrm{~J}$ & 3.3 & 0.0 & 0.0 & 0.0 & 0.0 & 0.0 & 0.0 \\
$\mathrm{~K}$ & 0.0 & 0.7 & 0.0 & 0.0 & 0.0 & 0.0 & 4.3 \\
$\mathrm{~L}$ & 12.3 & 14.9 & 4.8 & 22.2 & 17.2 & 8.3 & 21.8 \\
$\mathrm{M}$ & 5.2 & 7.8 & 9.5 & 11.1 & 11.0 & 4.2 & 0.0 \\
N & 1.9 & 0.7 & 0.0 & 11.1 & 0.0 & 0.0 & 0.0 \\
O'P & 5.8 & 7.1 & 9.5 & 0.0 & 12.5 & 0.0 & 0.0 \\
Q & 11.7 & 14.2 & 9.5 & 22.2 & 18.8 & 8.3 & 8.7 \\
R & 1.3 & 4.3 & 9.5 & 0.0 & 3.1 & 0.0 & 8.7 \\
\hline
\end{tabular}


A direct comparison with the Asian riding horse breeds shows that haplogroups $\mathrm{L}, \mathrm{B}$ and $\mathrm{Q}$ are frequently present in these breeds. Though, there are some distinct differences in haplotype frequencies between the breeds. The haplogroups $\mathrm{Q}$ and $\mathrm{L}$ are very frequent in Mongolian horses while Tuvinian horses cluster mainly in haplogroups B and L. The main haplogroup of Buryat horse is B while the frequent haplogroup $\mathrm{L}$ is rare in this breed. In Transbaikalian horses, the haplogroup $\mathrm{G}$ being the most frequent haplogroup in Kabardian horses is the clear dominant one. In the other breeds, this haplogroup is rather rare. The small number of Kirghiz horse is present in these haplogroups. In contrast to the Kabardian horses, Buryat horses show high frequencies in haplogroup I, Mongolian horses in haplogroups $\mathrm{M}$ and $\mathrm{O}$ 'P, and Tuvinian horses in haplogroup $\mathrm{H}$, respectively. Only the Transbaikalian horses show a high percentage of haplogroup A which seems to be common in Asian breeds (Achilli et al., 2012).

Altogether, the Kabardian horses distinguish from the Asian breeds in many haplogroup frequencies. Otherwise, the haplogroup structure of West European breeds with the dominant L (Cieslak et al., 2010) and Bulgarian mountain pony breeds with higher percentage of $\mathrm{M}$ and $\mathrm{J}$ is also quite different (Hristov et al., 2016). The best congruency can be found to horses from the Middle East (Achilli et al., 2012) with exception of East Anatolian horses (Koban et al., 2012) although the group $G$ has a higher percentage in Kabardian horses at expense of group L.

In breeds from Middle East (Ahkal Teke, Caspian), the haplogroup $\mathrm{L}$ is dominant followed by a mixture of A/B/G (McGahern et al., 2006a; Cieslak et al., 2010). But overall, the majority of haplotypes and haplogroups are not restricted to a certain geographical area or a specific breed. The phylogenetic tree of D-loop sequences produces no specific cluster (Fig. 1) albeit two or more breeds share the same haplotype only in $15 \%$ of all case. Differences only emerge in numbers and frequencies of haplotypes.

In addition, discrepancies in the haplogroup percentage result often from the limited number of investigated horses, which is often not representative for the entire breed. In consideration of the high diversity of D-loop region, these results can only show a tendency of haplogroup distribution in regions or breeds. Significant geographical separation or breeding effects on the haplogroup structure can only be detected in exceptional cases like breed isolation, limited number of founders as well as extremely rare haplotypes (Cardinali et al., 2016; McGahern et al., 2006a,b).

The lack of such specific haplotypes and the wide variability in Kabardian horses precludes a classification into a region or a group of breeds. But the very high mitochondrial haplotype diversity in horses is a well-known fact (Cardinali et al., 2016; Gemingguli et al., 2016).

Multiple, widespread and repeated domestication of diverse founder mares as well as mixed origin of most breeds are considered as likely causes for this phenomenon (Cozzi et al., 2004; McGahern et al., 2006a; Lei et al., 2009). In agreement with previous studies, only one to three horses share the same haplotype (Cozzi et al., 2004; Lei et al., 2009; Achilli et al., 2012; Bigi et al., 2014).

The haplotype diversity of Kabardian (0.980) is similar to that of the additional investigated Asian horses or higher. That also applies to comparison with other breeds like Arabian (0.784 and 0.962), Thoroughbred (0.883 and 0.942), Kazakh (0.977), Chinese (0.978 and 0.989 ) as well as Brazilian (varying from 0.200 to 0.944) horses (Zhang et al., 2012; Ianella et al., 2017; Othman et al., 2017).

However, the Kabardian horse has a huge genetic variability in its maternal lineages representing a diverse origin and a longstanding history, which is in agreement with recently published microsatellite analysis (Duduev et al., 2014).

Only a small diversity was found in the Y chromosome sequences (Table 4). Neither the Kabardian nor the Przewalski's stallions presented mutations proved in wild Siberian (M0147), Icelandic (M25345) and Fjord (M11007-11315) horses, respectively.

An old mutation (M0201) typical for pre-domestic horses and Przewalski's stallions (Lippold et al., 2011; Der Sarkissian et al., 2015) was also not found in Kabardian horse. Only two common domestic horse polymorphisms (M10594 and M1277) were present in Kabardian stallions leading to three haplotypes. The haplotype HT1 (T on position M1277 and M10594; after Wallner et al. (2013)) which was present in 36.7\% of the Kabardian stallions is the ancestral haplotype of domestic horses and the non-mutated variant $T$ was also found in Przewalski's horse.

Haplotype HT2 (A on position M1277 and T on M10594) originating from Arabian founders was also present with a high frequency of $38.8 \%$. This haplotype occurs frequently in breeds from Eastern and Central Europe as well as in breeds of the Middle East like Ahkal teke.

Beside these two old and widely spread haplotypes, $24.5 \%$ of the Kabardian stallions had haplotype HT3 (A on position M1277 and deletion on M10594). These stallions obtained their $\mathrm{Y}$ chromosome from the introgression of Thoroughbred. In the $19^{\text {th }}$ and at the beginning of the $20^{\text {th }}$ century, Thoroughbred stallions were carefully introduced for improving speed in combination with endurance. Around 1960, a second introduction of Thoroughbred created the Anglo Kabardian lineage (Dragilev, 1953) but this population was not investigated in our study. 


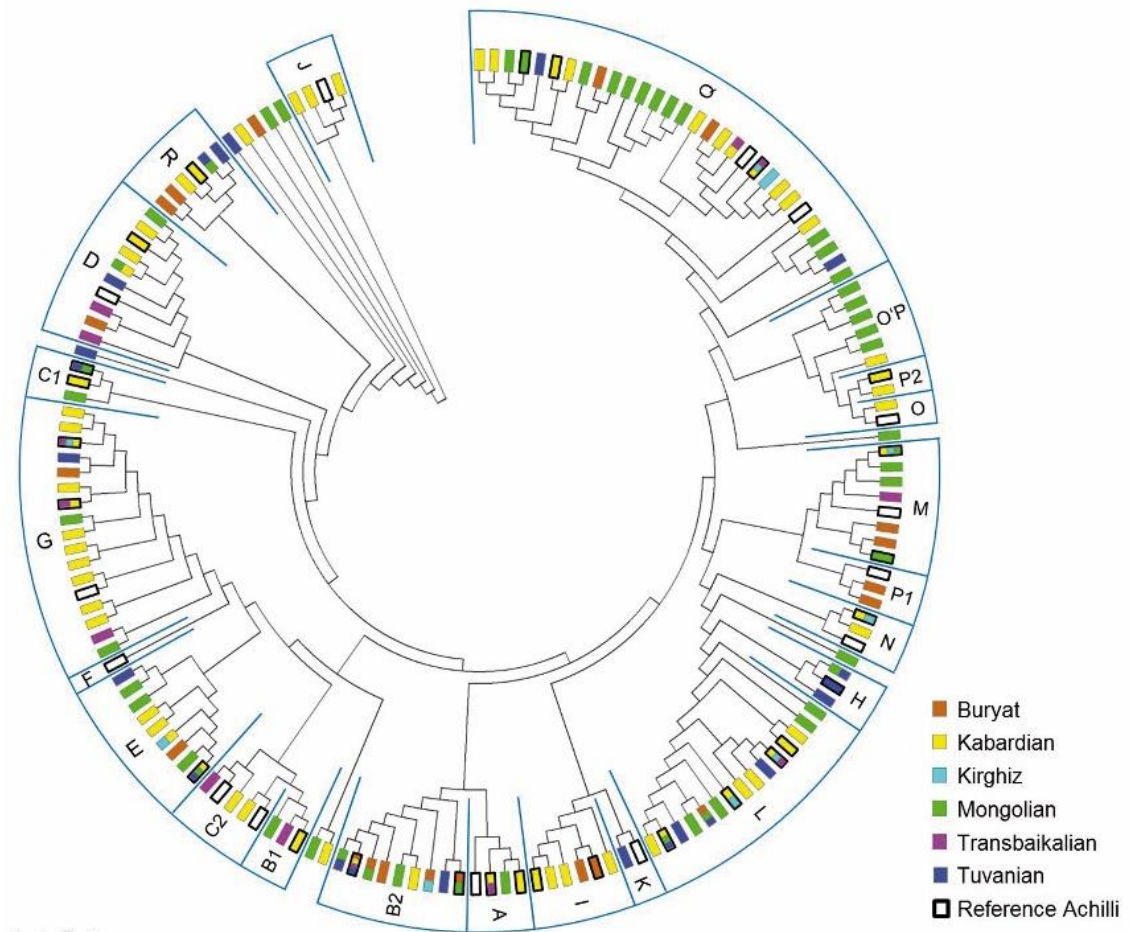

Fig. 1. Phylogenetic tree based on mtDNA D-loop sequences (309 bp from 15469-15777 with NC001640 from GenBank as reference) within 161 haplotypes (64 Kabardian, 20 Buryat, 9 Kirghiz, 50 Mongolian, 13 Transbaikalian, 22 Tuvinian). From GenBank, 40 additonal sequences - framed with thick black lines - were used for identification of haplogroup cluster (letters) after Achilli et al. (2012).

Table 4. Genotyping results for several mutations on equine Y chromosome (dash: not discovered).

\begin{tabular}{|c|c|c|c|c|c|c|c|c|c|c|c|c|c|}
\hline & \multirow{2}{*}{$\mathrm{n}$} & \multicolumn{2}{|c|}{$\mathrm{M} 0147^{1)}$} & \multicolumn{2}{|c|}{ M02011) } & \multicolumn{2}{|c|}{ M253452) } & \multicolumn{2}{|c|}{ M105942) } & \multicolumn{2}{|c|}{ M11007-113152) } & \multicolumn{2}{|c|}{ M12772) } \\
\hline & & $\mathrm{C}$ & $\mathrm{T}$ & $\mathrm{C}$ & G & $\mathrm{A}$ & $\mathrm{G}$ & $\mathrm{T}$ & Del & Normal & Mutated & A & $\mathrm{T}$ \\
\hline $\mathrm{aDNA}^{1)}$ & 4 & 3 & 1 & 0 & 4 & - & - & - & - & - & - & - & - \\
\hline Przewalski's & 4 & 4 & 0 & 0 & 4 & 0 & 4 & 4 & 0 & 4 & 0 & 0 & 4 \\
\hline Kabardian & 49 & 49 & 0 & 49 & 0 & 0 & 49 & 37 & 12 & 49 & 0 & 31 & 18 \\
\hline
\end{tabular}

${ }^{1}$ Mutation position and wild ancient horse (aDNA) results from Siberia after Lippold et al. (2011). ${ }^{2}$ Mutation position after Wallner et al. (2013).

Compared with the maternal variation, the paternallyinherited non-recombining Y chromosome diversity in horses is limited (Wallner et al., 2003; Lindgren et al., 2004; Ling et al., 2010; Kreutzmann et al., 2014) but with three paternal haplotypes, the Kabardian horse has a remarkable diversity.

This inside into the genetic structure of the Kabardian breed is helpfully for its future improvement. The great mitochondrial diversity without specific haplotype cluster can be considered as result of long-standing genetic exchange and admixture with other domestic horse lineages. The major haplogroup frequency is similar to that of Middle East breeds which argues for a closer relationship. The fact that two-thirds of the stallions go back to performance breeds (Original Arabian and Thoroughbred) emphasizes a continuous selection of the local stock for riding and endurance ability. There is no risk of inbreeding neither from maternal nor from paternal side.

\section{Acknowledgements}

This study was funded by the Volkswagen Stiftung, Germany (Az.: 85 858). We thank all Kabardian horse breeders for their support and Frau Schemmel (Humboldt University, Berlin) for helping with laboratory analysis.

\section{Conflict of interest}

The authors declare that there is no conflict of interests.

\section{References}

Achilli, A., Olivieri, A., Soares, P., Lancioni, H., Hooshiar Kashani, B., Perego, U.A., Nergadze, S.G., Carossa, V., Santagostino, M., Capomaccio, S., Felicetti, M., Al-Achkar, W., Penedo, M.C., Verini-Supplizi, A., Houshmand, M., Woodward, S.R., Semino, O., Silvestrelli, M., Giulotto, E., Pereira, L., Bandelt, H.J. and Torroni, A. 2012. Mitochondrial genomes from modern horses reveal the major haplogroups that underwent 
domestication. Proc. Natl. Acad. Sci. U S A 109(7), 2449-2454.

Alves, E., Ovilo, C., Rodriguez, M.C. and Silio, L. 2003. Mitochondrial DNA sequence variation and phylogenetic relationships among Iberian pigs and other domestic and wild pig populations. Anim. Genet. 34(5), 319-324.

Bigi, D., Perrotta, G. and Zambonelli, P. 2014. Genetic analysis of seven Italian horse breeds based on mitochondrial DNA D-loop variation. Anim. Genet. 45(4), 593-595.

Bowling, A.T., Del Valle, A. and Bowling, M. 2000. A pedigree-based study of mitochondrial D-loop DNA sequence variation among Arabian horses. Anim. Genet. 31(1), 1-7.

Brandariz-Fontes, C., Leonard, J.A., Vega-Pla, J.L., Backstrom, N., Lindgren, G., Lippold, S. and Rico, C. 2013. Y-chromosome analysis in Retuertas horses. PLoS One 8(5), e64985.

Cardinali, I., Lancioni, H., Giontella, A., Capodiferro, M.R., Capomaccio, S., Buttazzoni, L., Biggio, G.P., Cherchi, R., Albertini, E., Olivieri, A., Cappelli, K., Achilli, A. and Silvestrelli, M. 2016. An Overview of Ten Italian Horse Breeds through Mitochondrial DNA. PLoS One 11(4), e0153004.

Chauhan, M., Gupta, A.K. and Dhillon, S. 2011. Genetic diversity and population structure of three Indian horse breeds. Mol. Biol. Rep. 38, 3505-3511.

Cieslak, M., Pruvost, M., Benecke, N., Hofreiter, M., Morales, A., Reissmann, M. and Ludwig, A. 2010. Origin and history of mitochondrial DNA lineages in domestic horses. PLoS One 5(12), e15311.

Cozzi, M.C., Strillacci, M.G., Valiati, P., Bighignoli, B., Cancedda, M. and Zanotti, M. 2004. Mitochondrial D-loop sequence variation among Italian horse breeds. Genet. Sel. Evol. 36, 663-672.

Der Sarkissian, C., Ermini, L., Schubert, M., Yang, M.A., Librado, P., Fumagalli, M., Jonsson, H., BarGal, G.K., Albrechtsen, A., Vieira, F.G., Petersen, B., Ginolhac, A., Seguin-Orlando, A., Magnussen, K., Fages, A., Gamba, C., Lorente-Galdos, B., Polani, S., Steiner, C., Neuditschko, M., Jagannathan, V., Feh, C., Greenblatt, C.L., Ludwig, A., Abramson, N.I., Zimmermann, W., Schafberg, R., Tikhonov, A., Sicheritz-Ponten, T., Willerslev, E., Marques-Bonet, T., Ryder, O.A., McCue, M., Rieder, S., Leeb, T., Slatkin, M. and Orlando, L. 2015. Evolutionary Genomics and Conservation of the Endangered Przewalski's Horse. Curr. Biol. 25(19), 2577-2583.

Di Lorenzo, P., Ceccobelli, S., Panella, F., Attard, G. and Lasagna, E. 2015. The role of mitochondrial DNA to determine the origin of domestic chicken. World's Poultry Sci. J. 71(2), 311-318.

Di Lorenzo, P., Lancioni, H., Ceccobelli, S., Curcio, L., Panella, F. and Lasagna, E. 2016. Uniparental genetic systems: a male and a female perspective in the domestic cattle origin and evolution. Electronic J. Biotechnol. 23, 69-78.

Dragilev, P.I. 1953. [Working with horses of a new type - in Russian]. In Purebred Kabardin Stud Book Volume III. Ed. Ministry of Agriculture Kabardian ASSR, Nalchik.

Duduev, A.S., Khaudov, A.D., Kokov, Z.A., Amshokov, Kh.K., Zhekamukhov, M.Kh., Zaitsev, A.M., Zaitseva, M.A., Gavrilicheva, I.S., Kalinkova, L.V. and Reissmann, M. 2014. [Genetic structure of the Kabardian horse breed on DNA micosatellite loci and the possiblity of identification on population level by this method - in Russian]. Konevodstvo i konnyi sport (6), 18-19.

Forster, P., Hurles, M.E., Jansen, T., Levine, M. and Renfrew, C. 2012. Origins of the domestic horse. Proc. Natl. Acad. Sci. U S A 109(46), E3148; author reply E3149.

Gemingguli, M., Iskhan, K.R., Li, Y., Qi, A., Wunirifu, W., Ding, L.Y. and Wumaierjiang, A. 2016. Genetic diversity and population structure of Kazakh horses (Equus caballus) inferred from mtDNA sequences. Genet. Mol. Res. 15(4). doi: 10.4238/gmr.15048618.

Hristov, P., Yordanov, G., Ivanova, A., Mitkov, I., Sirakova, D., Mehandzyiski, I. and Radoslavov, G. 2016. Mitochondrial diversity in mountain horse population from the South-Eastern Europe. Mitochondrial DNA A DNA Mapp. Seq. Anal. 28(6), 787-792.

Ianella, P., Albuquerque, M.S.M., Paiva, S.R., Egito, A.A., Almeida, L.D., Sereno, F.T.P.S., Carvalho, L.F.R., Mariante, A.S. and McManus, C.M. 2017. D-loop haplotype diversity in Brazilian horse breeds. Genet. Mol. Biol. 40(3), 604-609.

Jansen, T., Forster, P., Levine, M.A., Oelke, H., Hurles, M., Renfrew, C., Weber, J. and Olek, K. 2002. Mitochondrial DNA and the origins of the domestic horse. Proc. Natl. Acad. Sci. U S A 99(16), 1090510910.

Khanshour, A.M. and Cothran, E.G. 2013. Maternal phylogenetic relationships and genetic variation among Arabian horse populations using whole mitochondrial DNA D-loop sequencing. BMC Genet. 14, 83.

Koban, E., Denizci, M., Aslan, O., Aktoprakligil, D., Aksu, S., Bower, M., Balcioglu, B.K., Ozdemir Bahadir, A., Bilgin, R., Erdag, B., Bagis, H. and Arat, S. 2012. High microsatellite and mitochondrial diversity in Anatolian native horse breeds shows Anatolia as a genetic conduit between Europe and Asia. Anim. Genet. 43(4), 401-409.

Kreutzmann, N., Brem, G. and Wallner, B. 2014. The domestic horse harbours Y-chromosomal microsatellite polymorphism only on two widely 
distributed male lineages. Anim. Genet. 45(3), 460. doi: 10.1111/age.12149.

Kumar, S., Stecher, G. and Tamura, K. 2016. MEGA7: Molecular Evolutionary Genetics Analysis Version 7.0 for Bigger Datasets. Mol. Biol. Evol. 33(7), $1870-1874$.

Lei, C.Z., Su, R., Bower, M.A., Edwards, C.J., Wang, X.B., Weining, S., Liu, L., Xie, W.M., Li, F., Liu, R.Y., Zhang, Y.S., Zhang, C.M. and Chen, H. 2009. Multiple maternal origins of native modern and ancient horse populations in China. Anim. Genet. 40(6), 933-944.

Lindgren, G., Backstrom, N., Swinburne, J., Hellborg, L., Einarsson, A., Sandberg, K., Cothran, G., Vila, C., Binns, M. and Ellegren, H. 2004. Limited number of patrilines in horse domestication. Nat. Genet. 36(4), 335-336.

Ling, Y., Ma, Y., Guan, W., Cheng, Y., Wang, Y., Han, J., Jin, D., Mang, L. and Mahmut, H. 2010. Identification of $\mathrm{Y}$ chromosome genetic variations in Chinese indigenous horse breeds. J. Hered. 101(5), 639-643.

Lippold, S., Knapp, M., Kuznetsova, T., Leonard, J.A., Benecke, N., Ludwig, A., Rasmussen, M., Cooper, A., Weinstock, J., Willerslev, E., Shapiro, B. and Hofreiter, M. 2011. Discovery of lost diversity of paternal horse lineages using ancient DNA. Nat. Commun. 2, 450.

Ludwig, A., Alderson, L., Fandrey, E., Lieckfeldt, D., Soederlund, T.K. and Froelich, K. 2013. Tracing the genetic roots of the indigenous White Park Cattle. Anim. Genet. 44(4), 383-386.

McGahern, A., Bower, M.A., Edwards, C.J., Brophy, P.O., Sulimova, G., Zakharov, I., Vizuete-Forster, M., Levine, M., Li, S., MacHugh, D.E. and Hill, E.W. 2006a. Evidence for biogeographic patterning of mitochondrial DNA sequences in Eastern horse populations. Anim. Genet. 37(5), 494-497.

McGahern, A.M., Edwards, C.J., Bower, M.A., Heffernan, A., Park, S.D., Brophy, P.O., Bradley, D.G., MacHugh, D.E. and Hill, E.W. 2006b. Mitochondrial DNA sequence diversity in extant
Irish horse populations and in ancient horses. Anim. Genet. 37(5), 498-502.

Miller, S.A., Dykes, D.D. and Polesky, H.F. 1988. A simple salting out procedure for extracting DNA from human nucleated cells. Nucleic Acids Res. 16(3), 1215.

Othman, O.E., Mahrous, K.F. and Shafey, H.I. 2017. Mitochondrial DNA genetic variations among four horse populations in Egypt. J. Genet. Engineer. Biotechn. 15(2), 469-474.

Rozas, J., Ferrer-Mata, A., Sánchez-DelBarrio, J.C., Guirao-Rico, S., Librado, P., Ramos-Onsins, S.E. and Sánchez-Gracia, A. 2017. DnaSP v6: DNA Sequence Polymorphism analysis of large Datasets. Mol. Biol. Evol. 34, 3299-3302.

Wallner, B., Brem, G., Muller, M. and Achmann, R. 2003. Fixed nucleotide differences on the Y chromosome indicate clear divergence between Equus przewalskii and Equus caballus. Anim. Genet. 34(6), 453-456.

Wallner, B., Palmieri N., Vogl C., Rigler D., Bozlak E., Druml T., Jagannathan V., Leeb T., Fries R., Tetens J., Thaller G., Metzger J., Distl O., Lindgren G., Rubin C.J., Andersson L., Schaefer R., McCue M., Neuditschko M., Rieder S., Schlötterer C. and Brem G. 2017. Y Chromosome Uncovers the Recent Oriental Origin of Modern Stallions. Curr. Biol. 27(13), 2029-2035.e5. doi: 10.1016/j.cub.2017.05.086.

Wallner, B., Vogl, C., Shukla, P., Burgstaller, J.P., Druml, T. and Brem, G. 2013. Identification of genetic variation on the horse y chromosome and the tracing of male founder lineages in modern breeds. PLoS One 8(4), e60015.

Yang, Y., Zhu, Q., Liu, S., Zhao, C. and Wu, C. 2017. The origin of Chinese domestic horses revealed with novel mtDNA variants. Anim. Sci. J. 88(1), 19-26.

Zhang, T., Lu, H., Chen, C., Jiang, H. and Wu, S. 2012. Genetic Diversity of mtDNA D-loop and Maternal Origin of Three Chinese Native Horse Breeds. Asian-Australas J. Anim. Sci. 25(7), 921-926. 